\title{
Local adaptation policy responses to extreme weather events
}

\author{
Leanne Giordono $^{1}$ (D) Hilary Boudet ${ }^{1} \cdot$ Alexander Gard-Murray $^{2}$ \\ Published online: 18 August 2020 \\ (c) Springer Science+Business Media, LLC, part of Springer Nature 2020
}

\begin{abstract}
At a global level, climate change is expected to result in more frequent and higher-intensity weather events, with impacts ranging from inconvenient to catastrophic. The potential for disasters to act as "focusing events" for policy change, including adaptation to climate change risk, is well known. Moreover, local action is an important element of climate change adaptation and related risk management efforts. As such, there is a good reason to expect local communities to mobilize in response to disaster events, both with immediate response and recovery-focused activities, as well as longer-term preparedness and adaptation-focused public policy changes. However, scholars also note that the experience of disaster does not always yield policy change; indeed, disasters can also result in policy inertia and failure, perhaps as often or more often than major policy change. This study poses two key research questions. First, we ask to what degree policy change occurs in communities impacted by an extreme weather event. Second, we seek to understand the conditions that lead to adaptation-oriented policy adoption in response to an extreme weather event. Our results suggest two main recipes for future-oriented policy adoption in the wake of an extreme weather event. For both recipes, a high-impact event is a necessary condition for future-oriented policy adoption. In the first recipe for change, policy adoption occurs in Democratic communities with highly focused media attention. The second, less expected recipe for change involves Republican communities that have experienced other uncommon weather events in the recent past. We use a comparative case approach with 15 cases and fuzzy set qualitative comparative analysis methods. Our approach adds to the existing literature on policy change and local adaptation by selecting a mid-N range of cases where extreme weather events have the potential to act as focusing events, thereby sidestepping selection on the dependent variable. Our approach also takes advantage of a novel method for measuring attention, the latent Dirichlet allocation approach.
\end{abstract}

Keywords Extreme weather $\cdot$ Climate change $\cdot$ Local government $\cdot$ Adaptation $\cdot$ Policy change $\cdot$ Focusing events

Electronic supplementary material The online version of this article (https://doi.org/10.1007/s1107 7-020-09401-3) contains supplementary material, which is available to authorized users.

Leanne Giordono

giordonl@oregonstate.edu

Extended author information available on the last page of the article 


\section{Introduction}

At a global level, climate change is expected to result in more frequent and higher-intensity weather events, with impacts ranging from inconvenient to catastrophic (Allen et al. 2018). The potential for disasters to act as "focusing events" that introduce windows of opportunity during which political actors compete to define the problem, identify solutions, and promote (or suppress) major policy change (Birkland 1997, 2006; Kingdon 1984; Rudel 2019), is well known. In the face of a changing climate, local communities, which are heavily engaged in emergency and disaster preparation and often bear the brunt of losses associated with disaster events (Crow et al. 2018; Reinhardt and Ross 2019; Vogel and Henstra 2015) might be expected to respond to extreme weather events with immediate response and recovery-focused activities, as well as longer-term climate change adaptationand mitigation-focused activities manifested as distinct policy changes.

However, policy change is context- and event-dependent, and scholars note that the experience of disaster does not always yield policy change. Indeed, disasters can also yield policy inertia and failure, perhaps as often or more so than major policy change (Birkland 1997, 2006; Boin et al. 2009; Nohrstedt 2008, 2011; Plein 2019). While few studies have examined local policy responses to extreme weather events, those that do find both that extreme events can lead to policy change, and that community- and event-specific conditions matter. For example, Mullin and Rubado (2017) find that local problem conditions and institutional capacity influenced the adoption of water usage restrictions in the context of local drought. Crow et al. (2018) find that disasters associated with Colorado floods acted as "windows of opportunity for learning," especially in the context of lower fiscal capacity and high disaster-related damage. And yet, not all catastrophic events lead to policy change, as shown by the policy inertia that characterized response to the 2016 catastrophic flooding in southern West Virginia (Plein 2019).

A larger body of literature is focused on individuals' climate change beliefs, discussion, and policy preferences in the wake of extreme weather events, though results are mixed. Despite broad evidence of political polarization on the issue of climate change (Dunlap and McCright 2008; Marquart-Pyatt et al. 2014), researchers have shown that personal harm from an event can change behavioral intentions and increase support for climate change policies (Demski et al. 2017; Zanocco et al. 2018, 2019). However, recent research also suggests that community action may not be as sensitive to climate change beliefs and discussion as previously imagined (Boudet et al. 2019; Javeline et al. 2019; Orlove et al. 2019). ${ }^{1}$

Extreme weather events therefore provide fruitful ground for learning more about the role of focusing events in local climate change adaptation and mitigation efforts. This study explores the conditions under which an extreme weather event, with a strong potential to function as a focusing event, yields local policy change. Weather events are exogenous at the local level, even when they are broadly attributed to human activity, strengthening our ability to infer a connection between the event and policy outcomes. This study poses two key research questions. First, we ask to what degree communities impacted by an extreme weather event enacted post-event policy change. Second, we seek evidence of the conditions that lead to adaptation-oriented policy change in response to an extreme

\footnotetext{
1 A previous study used these same 15 cases to assess community dialogue (Boudet et al. 2019). While this study draws on data and findings from the previous study, the current study examines a distinct dependent variable (policy change) and relies on a new conceptual framework and model-specific conditions.
} 
weather event. We selected 15 cases where extreme weather events have the potential to act as "focusing events," on the basis of Birkland's (1997, 1998, 2006) definition: events that are sudden, relatively rare, harmful and made known simultaneously to the public and policymakers virtually simultaneously. We expect that these cases will enable us to draw connections between extreme weather events and community-level adaptation-focused policy change.

Our approach fills several gaps in the literature. While the focusing events literature has contributed to our understanding of change at the national level, we know less about the conditions under which such events yield local policy change (Crow et al. 2018; Vogel and Henstra 2015), especially after extreme weather events, which may or may not yield catastrophic consequences. In contrast, the growing interdisciplinary literature linking extreme weather with climate change has focused primarily on individual attitudes and actions, yielding fewer insights about local policy actions resulting from such events. We take advantage of overlapping policy process and local climate change adaptation frameworks to develop a conceptual model of policy change in the wake of extreme weather events, contributing to the burgeoning adaptation (Palutikof et al. 2019). Moreover, while most studies select a small number of cases based on their responses to weather events, we select a mid-N number of cases (15) based on their exposure to extreme weather events, rather than their policy response, offering more variation in our cases and avoiding the problem of selection on the dependent variable (King et al. 1994). Finally, this study uses two novel methodological approaches: (1) fuzzy set qualitative comparative analysis, a set-theoretic approach for identifying combinations of conditions that lead to an outcome; and (2) latent Dirichlet allocation, a computational topic modeling approach that uses text-based analysis to measure attention and problem definition. ${ }^{2}$

We find a moderate level of policy change in response to extreme weather events. ${ }^{3}$ The largest share of policy measures was focused on anticipating and responding to future risk, followed by responses to current risks, and building risk management capacity. We find scant evidence of policies focused on mitigation that were proposed after an event. Enacted policies were relatively modest in scope, with few examples, if any, of pioneering policy innovations. We note two recipes for policy change. For both recipes, a high-impact event is a necessary condition for adaptation-oriented policy adoption. In the first recipe for change, policy adoption occurs in Democratic communities with relatively focused median attention. The second, less expected recipe for change occurs in majority Republican communities that have experienced other uncommon weather events in the recent past. Moreover, we also find two recipes accounting for policy stasis (i.e., not policy change), both of which reflect the experience of predominantly Democratic communities in the wake of low-impact and low-attention events. These results underscore previous observations about the power of focusing events, but importantly, suggest that political polarization and avoidance of climate change talk may not prevent communities from taking adaptation-oriented policy action after an extreme weather event. Thus, while there is substantial evidence of political polarization about climate change, our work aligns with recent media coverage (Flavelle 2020; Smith and Schwartz 2019) and scholarship (Boudet et al. 2019; Javeline et al. 2019; Orlove et al. 2019) highlighting the potential for communities to take action

\footnotetext{
${ }^{2}$ While neither of these methods are wholly new, they have been used only rarely in the policy process literature, offering an important methodological contribution.

3 For the purpose of this study, policy changes only include public policies proposed and enacted after the event at the local or regional (i.e., sub-state) level.
} 
even while refraining from, or even avoiding, discussions about climate change, especially in the context of high-impact events.

\section{Extreme weather events as potential "focusing events"}

Policy process scholars have long been interested in the determinants of policy change and conditions under which policy change occurs, in a variety of substantive arenas, including environmentally focused and disaster-inspired policy change. Birkland's (1997, 1998) development of the focusing events concept, inspired by Kingdon's (1984) seminal work on agenda-setting in the policy process has demonstrated the power of catastrophic events to act as focusing events (Birkland 2006; Birkland and Warnement 2016). While it is widely accepted that some events have the potential to act as focusing events, generating significant attention, mobilization, and policy change, less is understood about the conditions under which some events gain attention and yield community-level change, while others do not (Birkland and Warnement 2016; Nohrstedt and Weible 2010; Vogel and Henstra 2015). Concurrently, a growing body of interdisciplinary literature seeks to better understand the link between the experience of an extreme weather event and individual beliefs, policy preferences, and local action in response to future disaster risk in the face of a changing climate. We synthesize the insights from these complementary literatures to develop a broad conceptual framework, which we use to inform our analysis and interpretation of results. Specifically, we expect that combinations of event characteristics, features of the post-event debate, and community characteristics are likely to yield unique recipes for policy change, as shown in Fig. 1.

We expect that varying configurations of the three main conceptual elements from Fig. 1-event characteristics, community characteristics, and agenda-setting-will influence the degree of policy change focused on adaptation. For the purpose of this study, we are primarily focused on formal policy changes that are adopted at the local or regional
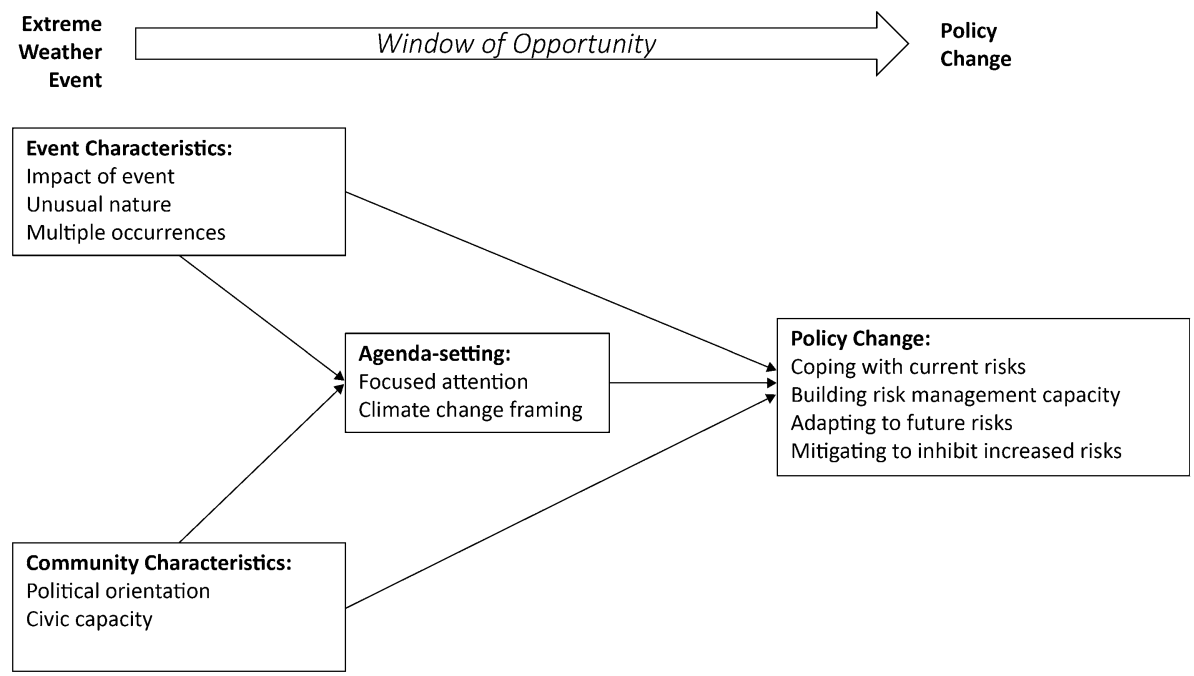

Fig. 1 Conceptual framework 
(i.e., sub-state) level. We define policy change as local resilience and adaptation policies that are expected to: (1) reduce community vulnerability to negative impacts of climaterelated change and/or (2) improve community capacity to adjust to climate-related change (Tiernan et al. 2019; Vogel and Henstra 2015). ${ }^{4}$ Motivation for the three main conceptual elements (event characteristics, community characteristics, and post-event attention) follows. ${ }^{5}$

\section{Event characteristics}

Both scholarship and anecdotal observation suggest that the characteristics of focusing events are critical to the policymaking process. Birkland's (2006) own definition of potential focusing events - events that occur suddenly, rarely and with actual or projected harm-suggests that we should expect these characteristics to matter in the policy making process, compared with everyday events that do not exhibit such features. Birkland and Warnement (2016) further distinguish between events that are (1) normal; (2) novel; or (3) normal with uncommon circumstances. Normal events include those events that are likely to occur over the course of time, but are nonetheless unpredictable (e.g., tornadoes, hurricanes, industrial accidents). These events are distinguished from novel events, which are both unpredictable and new in nature or influence (e.g., 9/11 attacks; COVID-19 pandemic). Normal events with uncommon circumstances gain attention primarily due to unique or unusual features of the event (e.g., Sandy Hook Elementary School shooting).

Accordingly, we anticipate that the impact of an event, with respect to losses and/ or government response, is likely to influence policy change. Moreover, impact may be mediated by the timeframe of event onset, with discrete and rapid-onset events and resultant impacts being more influential than ongoing or slow-onset events and impacts (Howe et al. 2014). While particular types of extreme weather events are not likely to be wholly novel in nature, we may expect that, as the climate changes, some types events may be either new to a specific geographic area, result in a remarkable amount of damage or affect a previously unaffected population. Furthermore, in the context of extreme weather, Sisco et al. (2017) find that the "abnormality" of events, in comparison with the historical record, is a significant predictor of climate change attention, while Boudet et al. (2019) find that events of unusual type or timing can lead to community climate change dialogue. Moreover, our interview findings suggested that in the cases we examined, a series of multiple extreme events in a short timeframe, especially "opposite" types of events (e.g., flood and fire; drought and flood) were connected to discussion of climate change and future risks. Some evidence suggests that repeated threats of disaster can yield public complacency (Wang and Kapucu 2008) and that repeated personal (negative) experience with disaster relief can undermine government authority (Darr et al. 2019). However, Cutter et al. (2018) note that "subjectively, people see an

\footnotetext{
${ }^{4}$ While we are aware that current scholarship is in the midst of theoretical distinctions about differences between resilience and adaptation, engaging in that discussion is outside the scope of this paper. Furthermore, some scholarship suggests that local climate change initiatives themselves make little distinction between the terms (Meerow and Neuner 2019), while other research suggests that the terms themselves reflect framing efforts by interested stakeholders (McEvoy et al. 2013). As such, we use the terms interchangeably.

5 Our approach to operationalizing these concepts is described in a separate section (Operationalization of Outcome and Causal Conditions).
} 
initial event as discrete, but by the second or third event the initial disaster no longer is understood as singularity but becomes intertwined in its effects and historical meaning with other events" $(2018,24)$. Accordingly, we expect that extreme weather events that have a strong impact on human lives and/or property, exhibit unusual patterns and/or co-occur with other unusual or extreme events, are necessary for policy change, but not sufficient in isolation.

By nature, disaster-focused research rarely examines non-disaster events, making it difficult to assess the influence of these characteristics on policy change. However, we can take observations of substantial variation in policy change in the wake of crises (Nohrstedt and Weible 2010) as suggestive of the insufficiency of extreme events alone in yielding policy change. While recent research substantiates the expectation that extreme weather events often lead to policy change, such changes are varied and far from inevitable. Crow et al. (2018), for example, describe changes in fiscal policy and related lessons learned among local governments in the wake of regional flooding in Colorado. Plein (2019) documents changes made in response to West Virginia flooding, although most policy changes were focused on recovery, rather than adaptation and resilience.

\section{Community and policy domain characteristics}

The IPCC report on local climate change adaptation efforts highlights the importance of contextualized adaptation strategies that take advantage of local culture, acknowledge cultural strengths and challenges, and build on existing local capacity as needed (Cutter et al. 2012). Accordingly, we expect two community characteristics to be relevant to the policy change process: political orientation and capacity.

Research consistently finds that political orientation plays a role in attitudes toward and beliefs about climate change, with self-identified liberals and Democrats more likely to believe in anthropogenic climate change (Albright and Crow 2019; Hamilton 2011), perceive increasing risks related to climate change (Hamilton et al. 2016; Marquart-Pyatt et al. 2014) and mobilize in information-seeking or activism (Boudet et al. 2019; Lang 2014), suggesting that party identification and/or political ideology are likely to influence support for policy change. However, the influence of political orientation on disaster response and policy is less clear. Recent media coverage suggests that some communities that avoid discussing climate change may simultaneously engage in actions intended to build capacity for risk management and/or adapt to future risk (Flavelle 2020; Smith and Schwartz 2019), an observation that has been borne out in recent research. Indeed, Javeline et al. (2019) find that actions by coastal homeowners are not associated with climate change beliefs, suggesting that post-event policy action may be equally likely among both Democratic and Republican communities.

Recent reviews of the adaptation and resilience literatures pay less attention to the influence of political orientation, instead emphasizing the importance of community capacity, including the presence of community leadership and community organizations (Tiernan et al. 2019; Vogel and Henstra 2015). Moreover, while the impacts of extreme weather events are often felt most dramatically at the local level, adaptation is shared both horizontally and vertically among multiple jurisdictions, such that local policy decisions are nested in a broader policy system (Nohrstedt and Weible 2010; Vogel and Henstra 2015). As such, we expect that a high community capacity for advocacy and mobilization to be an important condition for adaptation-oriented policy adoption, regardless of political orientation. 


\section{Agenda-setting}

Agenda-setting concerns the process by which policy communities mobilize to frame policy failures, problems, and solutions. In the post-crisis context, the nature of the agendasetting process is expected to be highly contextualized, with variation reflecting differences in policy domains and relevant policy communities (Birkland and Warnement 2016), as well as the degree to which the policies have "publics" (May 1991). Moreover, local contexts may differ substantially in the degree to which various groups have non-decisionmaking power, or the power to set the policy agenda and limit discussion of contentious issues (Lukes 2005), such as climate change. Vogel and Henstra (2015) suggest that climate adaptation policy is likely to be relatively low-salience without a "public" to seek and sustain attention. Salience may be further inhibited by difficulties in communicating the relevant scientific knowledge; see Tangney and Howes (2016). However, disasters may yield a sudden increase in salience and attention that open "windows of opportunity" (Kingdon 1984) during which policymakers and entrepreneurs have a chance to influence policy discourse. Indeed, recent studies demonstrate that disasters have "focusing power" (Vogel and Henstra 2015, 114) at the local level, prompting both dialogue and action. For example, Henstra (2012) finds that policymakers used a severe storm in Toronto, Canada, to motivate adaptation-focused dialogue and action. We expect that highly focused media attention on a particular topic in the wake of an extreme weather event to be a condition that leads to policy change, while more diffuse media attention across a wide range of topics to limit policy change post-event.

Similarly, framing has been shown to play an important role in policy changes by drawing on collective beliefs and influencing both discourse and outcomes (Boin 2009; Boin et al. 2009; McAdam 2017; McEvoy et al. 2013). For example, the argument for policy changes following a devastating storm in Sweden was framed in terms of a challenge to the crisis response system (Nohrstedt and Parker 2014). Similarly, Orlove et al. (2019) find that some glacial mountain communities draw more heavily on a community frame than a climate change frame when discussing adaptation projects, perhaps allowing them to bypass politically driven objections to adaptation policy. And in some cases, using a climate change frame to promote mitigation policy may be seen as exploiting event-related suffering (Boudet et al. 2019; Shepard et al. 2018) As such, we expect that dialogue about climate change may offer an important path to policy change, but that it is unlikely to be the only path.

\section{Methods}

Vogel and Henstra (2015) highlight comparative case study approaches as a promising method for gaining insight into local climate change adaptation and related policy change. We conducted a fuzzy set qualitative comparative analysis (fsQCA) of 15 cases of extreme weather events that occurred from 2012 to 2015. fsQCA is a set-theoretic approach that identifies configurations of causal conditions that are associated with observed outcomes of interest. The approach uses in-depth qualitative data to produce quantitative "scores" for outcomes and causal conditions associated with a mid-N set of cases and to 
identify necessary and sufficient configurations via Boolean algebra algorithms (Ragin 2000, 2008b). We used the "case-oriented" approach to fsQCA, which emphasizes "the substantive interpretability of results" $(2017,4){ }^{6}$

One advantage of fsQCA stems from its use of both qualitative and quantitative data to score and calibrate outcome and causal conditions, which offers distinct advantages compared to both traditional statistical approaches. First, fsQCA permits equifinality, or the possibility that multiple paths can lead to the same outcome. Second, fsQCA accommodates causal asymmetry, allowing the positive expression of the outcome to result from a distinct set of causal conditions, compared with negation of the outcome. Finally, conjectural causation, a hallmark trait of fsQCA, allows multiple causes to act in combination to influence an outcome. The approach also offers advantages relative to traditional comparative qualitative analysis (QCA), by introducing calibration of outcome and causal conditions that permits the analysis to move beyond the traditional QCA binary scoring approach. Unlike traditional qualitative comparative analysis, which uses similar techniques with binary $(0,1)$ conditions, fsQCA accommodates scores along the continuum from 0 to 1 , providing more opportunities to capture the rich variation available from qualitative data (Ragin 2000, 2008b).

\section{Case Selection}

We used the Spatial Hazard Events and Losses Database for the USA (Center for Emergency Management and Homeland Security 2018), also known as SHELDUS, as the main sampling frame for the study. The SHELDUS database provides county-level hazard data for US natural disasters; measures include event timing, location, property losses, crop losses, fatalities, and injuries. We limited our SHELDUS search to counties with weather events that caused fatalities and/or injuries between 2012 and $2014(N=392)$ and then supplemented these data with 2015 weather events reported by NOAA's Billion-Dollar Climate and Weather Disasters (NOAA National Centers for Environmental Information (NCEI) n.d.). ${ }^{7}$ To avoid over-sampling wealthy communities and under-sampling heatwaves, which yield little property damage (Tierney 2007), we did not use property or crop damage as a selection criterion.

After reviewing the initial sample, we selected events using a multi-step process. First, we selected events that resulted in at least 4 countywide fatalities $(N=39)$, with the intent of striking a balance between community impacts and the likelihood of media coverage. From among those cases, we further selected cases based on accessibility of a local (municipal or county) newspaper of record from the date of the event to 12 months after the event, with coverage of the identified event in sufficient detail (50 or more articles) $(N=24)$. From the resulting list of 24 potential cases, we then selected cases to cover different types of weather hazards: flooding, tornado, wildfire, landslide, winter weather, heat, and hurricane/tropical storm and all regions: Northeast, Southwest, West, Southeast, and Midwest. For multiple, co-located counties experiencing the same event as part of the same

\footnotetext{
6 This approach to fsQCA stands in marked contrast to the "condition oriented" approach, which emphasizes the "absence of redundancies" (Thomann and Maggetti 2017, 4). Neither approach has been definitively shown to be superior; indeed, a worldwide network of comparative researchers "rejects the position that a single solution type is always methodologically superior" (COMPArative Methods for Systematic cross-caSe analySis 2017,1 ).

72015 events were not available in SHELDUS at the time of case selection.
} 


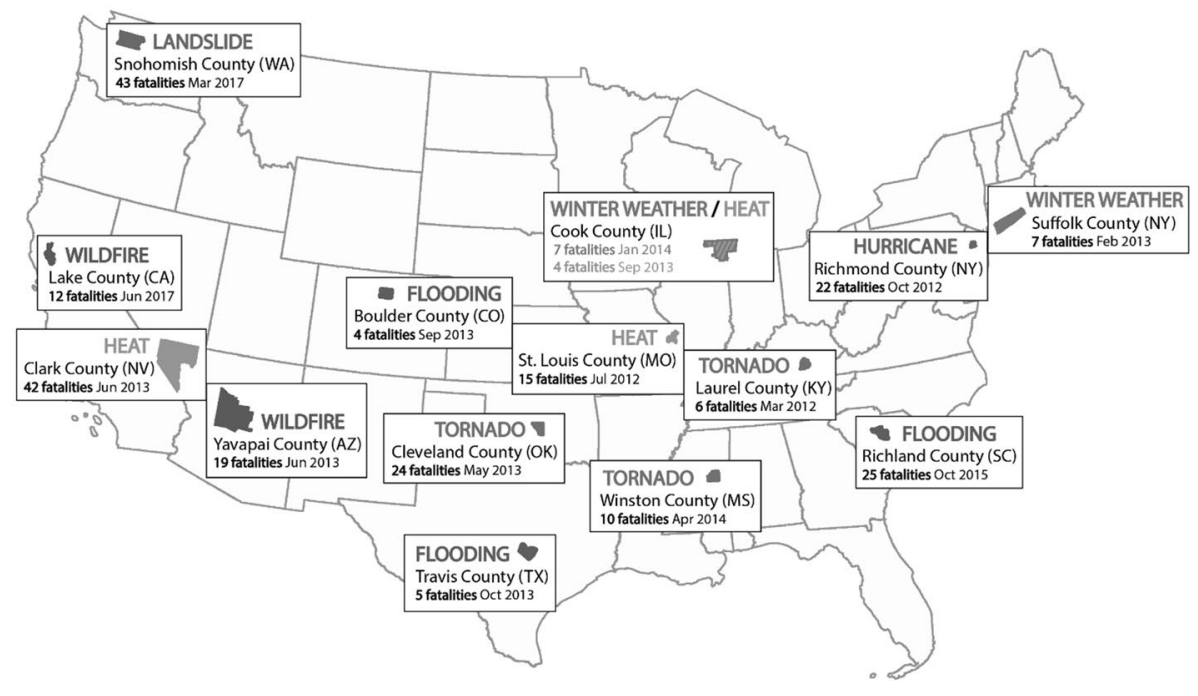

Fig. 2 Map of selected cases $(N=15)$, from Boudet et al. (2019)

weather system, we typically included the most impacted county in terms of fatalities in our analysis. Additionally, if the same weather event occurred in the same county 2 years in a row, only one of these years was selected as a case-again typically the event with the highest number of fatalities. When weighing inclusion of competing cases, a diversity of hazard types and geographic areas sometimes superseded the number of fatalities from the event. Figure 2 displays the selected cases with relevant characteristics. Online Appendix A1 includes selected information about each case, including location, event, and number of injuries and fatalities.

\section{Data collection}

We began with a systematic search for articles and editorials about the event published in the year after its occurrence, following McAdam and Boudet's (2012) advance preparatory fieldwork strategy. We supplemented the initial search with a second systematic search for the terms "climate change" and "global warming" in the year prior to the event and within the articles and letters focused on the event in the year after. We coded all relevant newspaper articles $(N=4610)$ and editorials $(N=203)$ to identify leaders and key policy actors, groups and organization, events and meetings, and proposed policies. Secondary data for county-level socioeconomic, demographic, organizational capacity, and event-related indicator were collected from multiple sources, including the US Census Bureau's American Community Survey (n.d.), the National Center for Charitable Statistics (National Center for Charitable Statistics n.d.), Yale Climate Opinion Maps (Howe et al. 2014), National Academies Report on Event Attribution (National Academies of Sciences, Engineering, and Medicine 2016). The newspaper and secondary data served as the primary sources for development of a preliminary case narrative, systematically structured to highlight our understanding of the weather event, related mobilization, and policy responses and to identify potential site visit and telephone interview contacts. 
We conducted a site visit to each case location, where we conducted interviews with key policy actors, including local and state elected officials, county/city staff, newspaper reports, leaders of local community organizations, and religious leaders. We logged a total of $128 \mathrm{~h}$ over the course of 164 interviews, averaging $47 \mathrm{~min}$ per interview. While on site, we also attended relevant public meetings and conducted additional interviews, as suggested by our initial contacts. Online Appendices A2 through A7 include detailed information about newspaper and interview data by case, including sources, counts, and interview duration and protocols. For each case, we developed a detailed research memo write-up that systematically synthesized information from interviews, newspaper articles, and secondary sources (Online Appendix A8). We used the case data in these write-ups, as well as the original articles, interviews, and secondary data, to develop the outcome and selected causal condition.

\section{Operationalization of outcome and causal conditions}

Our primary research objectives were to identify (1) the degree of local adaptation-focused policy change occurring in response to extreme weather events and (2) the combination(s) of conditions leading to the presence or absence of adaptation-focused policy change. We operationalized our outcome and causal conditions based on both theoretical considerations and our empirical evidence derived from the cases. See Online Appendices A10-A19 for detailed information about the development of conditions, including a codebook associated with the outcome conditions, as well as underlying data and calibration methods associated with all conditions.

\section{Outcome of interest}

Our primary outcome of interest, adaptation- and/or mitigation-focused policy change, which we refer to simply as "policy change," represents the degree to which the community enacted post-event public policies intended to address disaster-related risks. We searched newspaper articles and interview transcripts to compile evidence of local (and non-local) policy change and categorized each identified policy according to its proposal date (pre- or post-event), venue (private, administrative, legislative, ballot initiative, judicial), and jurisdiction (local/regional, state, national). ${ }^{8}$ For the purpose of this study, only policies that were local, public, and proposed after the event were retained in the data set for scoring and analysis.

The IPCC report (Cutter et al. 2012) identifies three main categories of potential policy change: (1) coping with current data risk; (2) building capacity to manage risk; and (3) anticipating and responding to future data risk. We used insights from the IPCC report (Cutter et al. 2012) to categorize each policy according to one of 10 sub-categories, representing three major risk management categories, as shown in Fig. 3.

The first group of policies, "Coping" measures, reflect how local places modify the impacts of disruptive events, features of the events themselves, and/or share or reduce the

\footnotetext{
${ }_{8}$ We primarily used newspaper coverage as our primary data source of systematic information about policy proposals and adoption, and interview transcripts for verification and additional information about the proposed policy and/or policy adoption status. We did not do a systematic search of other public documents; however, making it possible that our database does not include all proposed or adopted policies.
} 

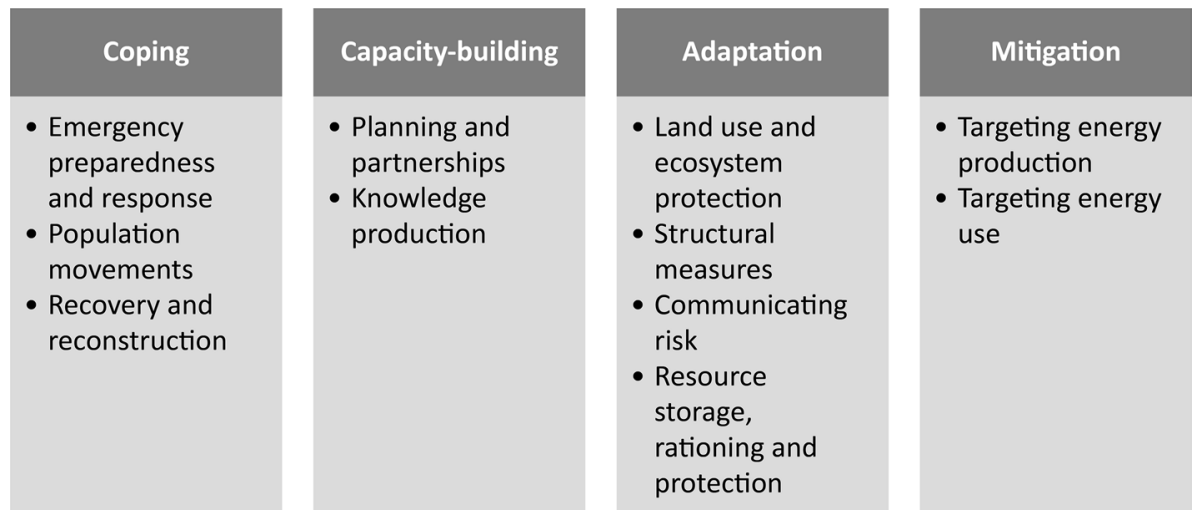

Fig. 3 Post-event policy categories and sub-categories, drawn from Cutter et al. (2012)

burdens of disaster risk. They include measures intended to improve the immediate capacity to respond to the event or similar events (e.g., equipment purchase, coverage of reliefrelated expenses, measures to prevent interference with emergency response), move people in response to an event (e.g., relocation) and/or rehabilitate and rebuild in response to the event (e.g., investments in new housing, changing building codes to encourage rebuilding). The second group, "Capacity-building" policies, includes those that build the capacity of a community to manage future risk, such as long-range planning and knowledge production that is intended to improve the community or region's ability to respond to future events. The third group, "Adaptation" policies, include land use and ecosystem protection measures (e.g., zoning changes, land acquisition, and resource management), structural measures (e.g., seawalls, measurement systems, and building codes, etc.), risk communication measures (e.g., warning systems, information channels, etc.), and resource storage, rationing protection (e.g., water rationing, medical triage systems, security measures). The last group, "Mitigation" policies, include those target energy production and/or use at the local level (e.g., municipalization of energy production facilities, adoption of energy use reduction strategies) with an eye to limiting the rate or magnitude of climate change. See Online Appendix A11 for a description of each of these categories and codebook.

Each policy measure was independently assigned to one (mutually exclusive) IPCCbased sub-category by two coders. After one reconciliation and independent recoding process, our coding efforts yielded a Cohen's kappa of 0.865 across individual policy categories and a Cohen's kappa of 0.837 across the four broad groups, indicating strong reliability (Cohen 1960; McHugh 2012).

Following Ragin (2006), we aggregated across these categorizations to create a macrocondition that ranged from 0 (fully out of the set) to 1 (fully in the set), prioritizing (1) land use/ecosystem protection and structural measures; and (2) policy change portfolios with a selection of new policies across all three categories. For example, for a case to be considered fully in the set of post-event policy change, we required evidence of either a new land use or structural policy, plus evidence of at least one recovery-focused policy and one capacity-building policy. We chose to privilege land use/ecosystem protection and structural measures based on the recognition that such policies, which tend to require broad support, political will, and considerable resources, can be an indicator of community investment in future-oriented adaptation. Cases fully out of the set of post-event policy change 
included those without any evidence of land use or structural measures, and no evidence of any new recovery or capacity-building policies. See Table 1 for detailed information about the fuzzy set scoring process.

\section{Causal conditions}

We operationalized three types of causal conditions, based on the literature, including (1) event-specific characteristics; (2) context characteristics; and (3) post-event attention. We briefly discuss the operationalization of each of these categories in turn below. Operationalization of each causal condition is presented in Table 2, with each causal condition scored along a continuum from 0 to 1 , in standard fsQCA fashion. The underlying data and calibrated score for each causal condition are provided in Online Appendices A11-A18.

\section{Event characteristics}

While all of our cases can be described as non-typical weather events, on the basis of our fieldwork, we identified three characteristics for which we expected variation to influence the degree and type of event-related attention: (1) event impact; (2) event unusualness; and (3) exposure to multiple extreme events.

Event impact was scored using a combination of the total number of fatalities, the number of fatalities experienced in a 24-h period, and the issuance of a Presidential disaster declaration, with the highest impact events being those with 10 or more fatalities in 1 day and issuance of a Presidential declaration. We used a combined measure of unusualness and exposure to multiple extreme events to measure events likely to represent an uncommon event, above and beyond its extreme nature. The unusualness of the event was scored on the basis of the event type and timing; events with the highest score are those that were described as not normal for the area in terms of both type and timing. We scored recent exposure to multiple extreme events with a combination of the number and type(s) of extreme events that occurred within a year prior to the event of interest. Cases with the highest score on this causal condition included those that had experienced at least two events of opposing type (e.g., flood and fire, drought and flood); communities that had experienced at least multiple extreme events of the same type during a 1-3 years period were still in the set of multiple-occurring, but at lower scores.

\section{Community characteristics}

As suggested by our conceptual framework, we posited that two community characteristics, political orientation and environmental civic capacity, would be relevant to our analysis. For each county where our 15 events took place, we measured political orientation as the percent of voters who voted Democratic in the most recent pre-event Presidential election (2008 or 2012), following Levandusky et al.'s (2008) finding that presidential voting patterns are a good proxy for local partisanship. We measured local civic capacity as the pre-event number of nonprofit organizations per capita in the county, using data on the presence of nonprofits from the National Center for Charitable Statistics (National Center for Charitable Statistics n.d.) and aggregate population data from the American Community Survey (US Census Bureau n.d.). Both measures were then calibrated using Ragin's (2008a) direct method of calibration for conventional interval-scale indicators. Our theoretical expectations for community civic capacity was positive; we expected to see cases with 
Table 1 Outcome operationalization

\begin{tabular}{|c|c|c|}
\hline Outcome & $\begin{array}{c}\text { Scoring } \\
\text { (\#) }\end{array}$ & Scoring (def) \\
\hline \multirow[t]{6}{*}{$\begin{array}{l}\text { POLICY CHANGE: } \\
\text { Adaptation- and/or } \\
\text { mitigation oriented } \\
\text { policies proposed and } \\
\text { enacted after event }\end{array}$} & 0 & $\begin{array}{l}\text { \# Land-use policies }=0 \text { AND \# Structural policies }=0 \\
\text { AND } \\
\text { \# Current risk management policies }=0 \mathrm{AND} \\
\text { \# Other future-orien ted policies }=0 \mathrm{AND} \\
\text { \# Capacity-building policies }=0\end{array}$ \\
\hline & 0.2 & $\begin{array}{l}\text { \# Land-use policies = } 0 \text { AND \# Structural policies }=0 \\
\text { AND } \\
\text { \# Current risk management policies }>0 \text { OR } \\
\text { \# Other future-orien ted policies }>0 \mathrm{OR} \\
\text { \# Capacity-building policies }>0\end{array}$ \\
\hline & 0.4 & $\begin{array}{l}\text { \# Land-use policies }=0 \text { AND \# Structural policies }=0 \\
\text { AND } \\
\text { \# Current risk management policies }>0 \text { AND } \\
\text { \# Other future-orien ted policies }>0 \text { AND } \\
\text { \# Capacity-building policies }>0\end{array}$ \\
\hline & 0.6 & $\begin{array}{l}\text { \# Land-use policies }>0 \text { OR \# Structural policies }>0 \\
\text { AND } \\
\text { \# Current risk management policies }=0 \text { AND } \\
\text { \# Other future-orien ted policies }=0 \text { AND } \\
\text { \# Capacity-building policies = } 0\end{array}$ \\
\hline & 0.8 & $\begin{array}{l}\text { \# Land-use policies }>0 \text { OR \# Structural policies }>0 \\
\text { AND } \\
\text { \# Current risk management policies }>0 \text { OR } \\
\text { \# Other future-orien ted policies }>0 \text { OR } \\
\text { \# Capacity-building policies }>0\end{array}$ \\
\hline & 1.0 & $\begin{array}{l}\text { \# Land-use policies }>0 \text { OR \# Structural policies }>0 \\
\text { AND } \\
\text { \# Current risk management policies }>0 \text { AND } \\
\text { \# Other future-orien ted policies }>0 \text { AND } \\
\text { \# Capacity-building policies }>0\end{array}$ \\
\hline
\end{tabular}




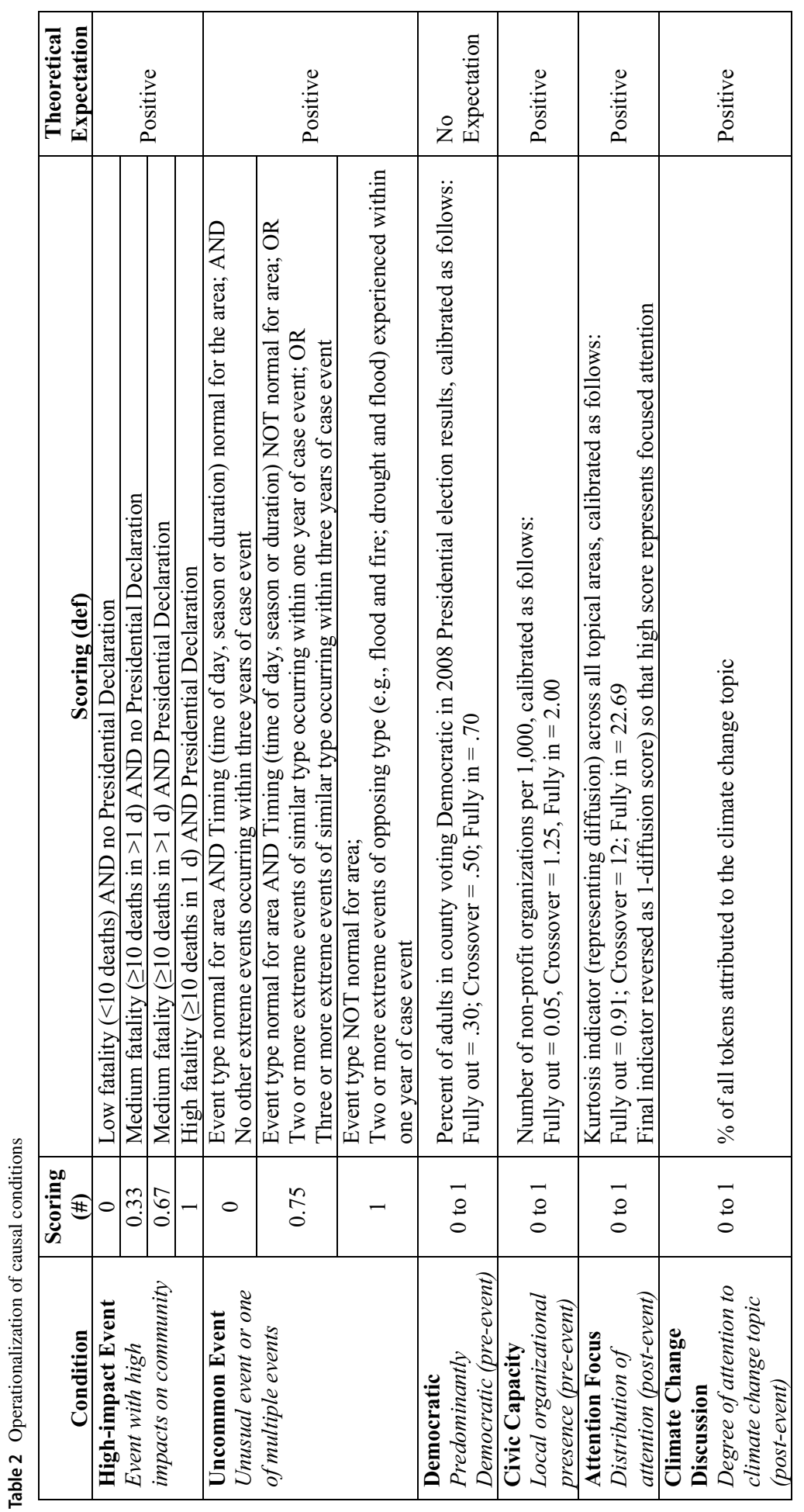


either of those characteristics also present in the set of cases exhibiting post-event policy change. We did not have a theoretical expectation for percent Democratic; while substantial literature points to political orientation as an important determinant of attitudes toward climate change, our knowledge of the cases and selected literature suggested that we might find majority Republican cases exhibiting policy change, but without framing their action using climate change language.

\section{Features of post-event attention}

We measured post-event attention with two main indicators: (1) attention focus and (2) climate change discussion. Both indicators were developed by applying latent Dirichlet allocation (LDA), a form of computational topic modeling, to local newspaper articles covering the event in the year after its occurrence. LDA identifies the topics being discussed across a group of documents (Blei et al. 2003). LDA operates by clustering words that appear in a group of documents based on their co-occurrence within individual documents. Words that often appear together are (by assumption) more likely to be part of the same topic. Though relatively new, LDA has recently begun to be applied to studying climate change discourse (Cody et al. 2017).

To measure attention focus, we used the kurtosis of the distribution of topics within each newspaper's coverage. This is a standard statistical measure which represents whether a distribution is more or less concentrated. Lower kurtosis indicates a narrow-tailed distribution, meaning that coverage is focused on a relatively small number of topics. Higher kurtosis indicates a heavy-tailed distribution, with more diffuse discussion of topics. In our data, attention focus ranged from a low of 2 (relatively focused) to a high of 22 (relatively diffuse). See Online Appendix A9 for a more detailed account of the LDA method used in this study. We inverted the scale and normalized it to vary from 0 to 1 via calibration (Ragin 2008a), so that a high fuzzy score would represent cases with focused attention.

Our measure of climate change discussion was the share of newspaper coverage clustered into the LDA-generated topic that we identified as being devoted to climate change. While a fairly small proportion of coverage was devoted to climate change, the percentage ranged from less than 1 to $7 \%$, allowing us to calibrate the measure following Ragin (2008a).

\section{Analysis}

We used Ragin's (2000, 2008b) method of fuzzy set qualitative comparative analysis (fsQCA), a set-theoretic approach used to identify necessary and sufficient combinations of causal conditions, to explain variation in post-event policy response in the selected communities. According to standard fsQCA methods, a necessary causal condition (or combination of conditions) is identified when the outcome is shown to be a subset of the condition. In other words, there are no cases of the outcome being present with the necessary condition absent, and for all cases where the outcome is present, the necessary condition is also present. Consistency and coverage are the two standard measures for assessing the strength of the causal relationship between causal conditions and the outcome of interest. Set-theoretic consistency reflects the degree to which cases with the same condition or combination of conditions also share the outcome of interest (Ragin 2006). Strong evidence of necessity is indicated by the standard statistic, Consistency of Necessity (inclN) greater than 0.9, especially in the context of a high Relevance of Necessity (RoN). The standard measure for 
assessing sufficiency is Proportional Reduction in Consistency (PRI); a PRI score above 0.8 provides strong evidence of sufficiency. (Ragin 1987, 2008a; Schneider and Wagemann 2012) Coverage represents the degree to which a specific condition or configuration of conditions explains occurrences of the outcome of interest among the selected cases. Coverage is typically measured by raw coverage score (CovS); a higher CovS typically indicates that the given causal condition is more empirically relevant (Ragin 2006).

Following (Ragin 2008a), we began by conducting tests of necessity for all hypothesized causal conditions, followed by tests of sufficiency. Per Schneider and Wagemann (2012), we conducted analysis of necessary and sufficient conditions as separate analyses and used standard metrics to assess the consistency and coverage of various models. The intermediate solution from all tests of sufficiency is presented in the text. Finally, we conducted extensive sensitivity testing to assess the robustness of our findings, following Schneider and Wagemann's (2012) exhaustive enumeration approach. All fsQCA analyses were conducted in R 3.5.3 using the 'QCA' package 3.6 described by Duşa (2019) and Thiem and Duşa (2013).

We documented our analytic choices in extensive detail, as recommended by Schneider and Wagemann (2012), and in alignment with recent studies conducted by Boudet et al. (2019) and van der Heijden (2017). See Online Appendix A19 for a detailed description of our analytic approach and technical information about fsQCA statistics used to assess necessity and sufficiency. See also online replication files. ${ }^{9}$

\section{Results}

\section{Local policy change post-event}

Among the 15 cases, we identified 74 distinct policies that were formally proposed and adopted at the local level following these extreme weather events, ranging from 0 to 18 policies per case. ${ }^{10}$ As shown in Fig. 4, the highest prevalence policy measures included emergency preparedness and response (17 policies) and planning and partnership initiatives (17), followed by structural measures (12) and land use/ecosystem protections (8). By major policy category, the largest share of policy measures included efforts to anticipate and respond to future disaster risk (31; shaded gray), followed by policies to cope with current disaster risks (24; horizontal lines). Finally, a little over one-quarter of all policy measures were devoted to capacity-building activities (19; dots).

For our fuzzy set scoring, ten of the 15 cases scored in the set of cases that enacted policy changes post-event (i.e., score $>0.5$ ). Those cases showed evidence of structural and/ or land use/ecosystem protection policy change(s), and most of them also adopted current-, future- or capacity-oriented policy. Three cases, including Lake County (CA), Richmond County (NY), and Travis County (TX), were fully in the set of events facilitating adaptation-focused policy change (i.e., score $=1$ ), having enacted both structural and land use/ ecosystem policies, as well as policies in all of the three main categories. These top scoring

\footnotetext{
9 Replication files are available at https://osf.io/96ebk/?view_only=763fa5beaa0f4833bcac796dfd5f53e7.

${ }^{10}$ Even though the research question in this study was focused on local policies (including regional policies), it is worth noting that including state and national policy measures almost doubles the number of enacted policies to 145 , suggesting that these cases are, indeed, nested in the broader state and federal system.
} 


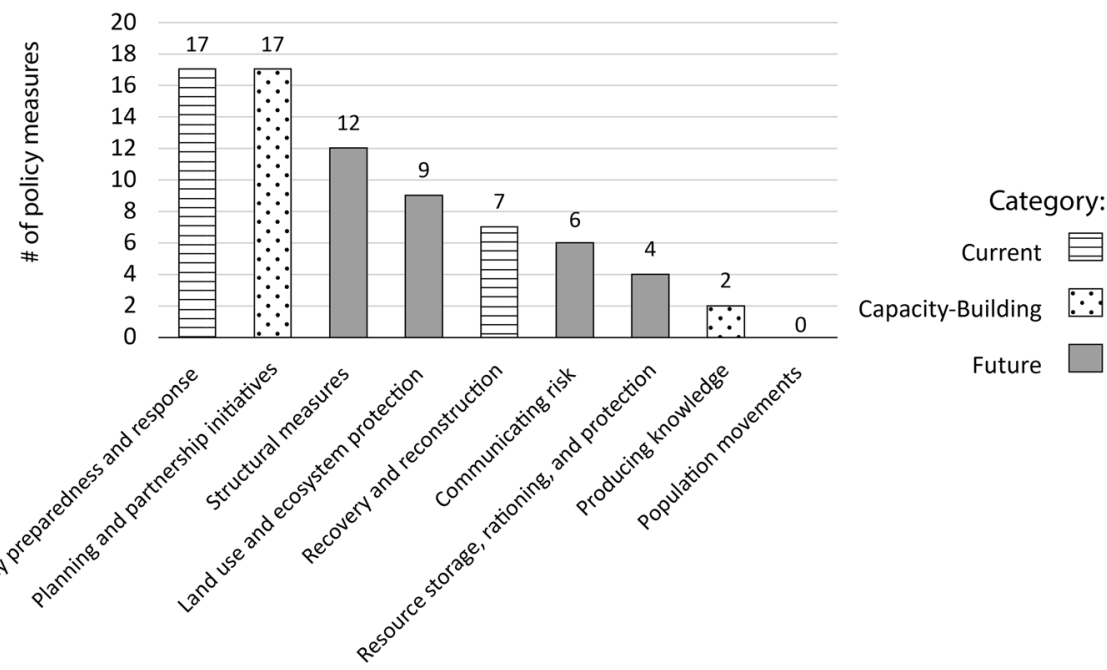

Policy measure sub-category

Fig. 4 Number of policy measures by sub-category $(N=74)$

cases, which included a wildfire, flood, and hurricane, were diverse with respect to event type.

Despite evidence of policy change, it is important to note that qualitatively, few of these policy changes represented a full-blown shift in goals and values, or even in the means by which communities hedge against disaster risk. Nor were most policies particularly innovative in nature. Instead, as anticipated by policy change theory, they represented incremental changes to existing systems, sustaining status quo power structures and validating prevailing policy beliefs. Indeed, evidence from our interviews suggests that some communities had already made relevant changes in response to events that occurred two to three decades earlier. That said, some communities took steps to reassess and adopt new goals, especially in relation to climate change and disaster risk management. For example, in Richland County (SC), Disaster Recovery Chief Mike King noted that in the wake of 2015 floods "We are now looking at replacing at the level that FEMA recommends, not just... replac[ing] the same old culvert with the same old culvert. What we want to do is...to mitigate in every step forward now, try to mitigate future events because, it's going to happen again, with climate change, it's going to happen again." (Interview 75) Other communities found that the experience of a major disaster opened the way to discussions about policy change. In Richmond County (NY), the widespread devastation associated with Hurricane Sandy yielded extensive attention to the topic of climate in both local and national media, resulting in a wide variety of policy changes focused on adapting to future risks. One of the newspaper articles, for example, states, "As much as New Yorkers would like to believe Hurricane Sandy is a once-in-a-lifetime event, the city is not taking any chances, especially as the science of climate change points to more such superstorms in our future" (Article 2031). This sentiment was echoed by several interviewees, such as Reverend Karen Jackson, Director of Recovery and Community Initiatives at Project Hospitality, who stated 
“...New York City is vulnerable, and therefore we need to be prepared for the next Sandy, which will happen” (Interview 83).

\section{Recipes for post-event policy change}

Not surprisingly, we found that the impact of the event was an important motivating factor for policy change. Indeed, our results indicate that a high-impact event was a necessary condition for policy change. In other words, most cases of policy change were in the subset of cases that experienced a high-impact event, while there were no cases of policy change that were in the set of low-impact events. In our test of necessity, the high-impact condition yielded a inclN (Consistency of Necessity) score of $0.88 .{ }^{11}$ See Online Appendix A20 for more detailed presentation of the results from these tests and our interpretation.

In the set of communities that enacted policy change, articles and interviews indicated that the community had been devastated by the high number of fatalities and/or populations affected. For example, in Cleveland County (OK), several children died during school hours when a tornado struck Moore, OK (Hampton 2013; Kinney 2013). These deaths were described by interviewees as emotionally devastating and directly connected to subsequent policy change. Robert Romines, the Superintendent of Moore Public Schools stated, "Buildings are easy to rebuild, but the loss of life and the seven kiddos that we lost, that is very hard to stomach," and went on to describe significant public interest and engagement related to a ballot measure funding storm shelters in every school (Interview 29).

In contrast, in most of the communities that did not enact adaptation-focused policy measures, the human impact was low and the event did not yield a strong sense of urgency with respect to government intervention. All of these cases represented extreme temperature events that occurred in the context of an effective emergency response system, in part due to extreme weather events experienced decades earlier. In St. Louis (MO), for example, all 11 interviewees referred to the impacts of the "big daddy" heatwave that hit St. Louis in the summer of 1980, when more than 150 St. Louis Metropolitan area residents died of heat-related causes and which motivated a series of key policy changes. Such changes likely lessened the impact of the 2012 heatwave yielding policy changes that were more limited in scope and focused more on "tweaking" past changes. In the one community, Suffolk County (NY), that experienced a high-impact event (blizzard), with a Presidential declaration but a low number of fatalities; the majority of the resulting policy changes were focused on managing current disaster risk (e.g., snowplow purchases).

Our analysis of sufficient conditions yielded two distinct configurations, or "recipes," of other event-related conditions, community characteristics, and features of the agendasetting process, associated with post-event policy change. The overall sufficiency test associated with these causal combinations yielded both high consistency $(\mathrm{PRI}=0.835)$ and coverage ( $\operatorname{cov} S=0.842$ ), as shown in Fig. 5 and described in more detail below. See Online Appendices A22-A24 for the truth table and results from our sufficiency analysis, as well as the results from our sensitivity testing process.

\footnotetext{
11 While this score is just below the standard 0.9 inclN cutoff for necessary conditions, a high RoN (Relevance of Necessity) of 0.80 and a high CovN (Coverage of Necessity) score 0.85 , suggest that we can reasonably infer that high-impact is a necessary condition among our sample of cases.
} 
High Impact Event*

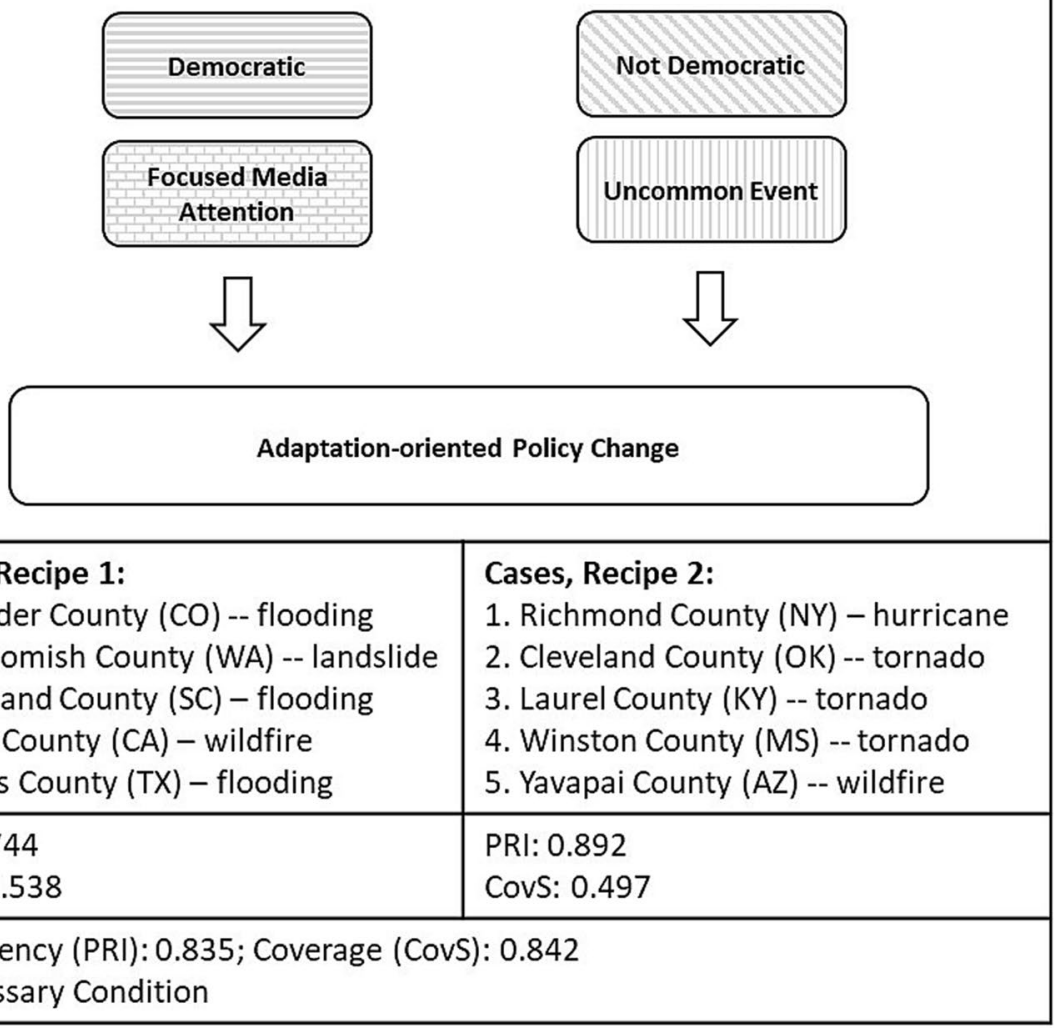

Fig. 5 Causal combinations related to post-event policy change

\section{Recipe 1: Democratic AND focused attention}

The first causal combination yielded post-event policy change with moderate consistency (0.744) and coverage (0.538). This recipe to policy change was marked by a high-impact event occurring in a Democratic county with relatively high post-event media attention. Cases in this recipe included flooding events in Boulder County (CO), Richland County (SC), and Travis County (TX), as well as the Snohomish County (WA) landslide and the Lake County (CA) wildfire, all of which were in the set of policy change cases (i.e., fuzzy set score $>0.5$ ). Three of the five cases were fully in the set of adaption-focused policy adoption, with policies focused on land use/ecosystem protections or structural measures, as well as policies focused on building capacity and coping with current risks.

Lake county (CA) The "Valley Fire" that occurred in Lake County, California, in autumn 2015 was the third most destructive wildfire in California's history at the time (Lake 
County Record Bee 2015a). Governor Brown declared a state of emergency for Lake County the day of the fire, and President Obama declared it a major disaster a week later (Krohn 2015; Lake County Record Bee 2015b). The fire, which occurred in the midst of a major 5-year drought, burned 76,067 acres, caused the evacuation of nearly 20,000 residents, and destroyed 1958 structures (Faries 2015a, b; Lake County Record Bee 2015a, c; Quirino 2015). Ultimately, the fire displaced 3700 residents, nearly $6 \%$ of Lake County's population. Lake County voted majority Democratic (56\%) in the 2012 Presidential election.

In response to the fire, Lake County enacted as many as 18 distinct policy measures across all three categories of adaptation policy. Most policies were oriented toward adapting to future disaster risk, ranging from installation of a 300-foot fire break, plans and grant requests for activities to reduce fuel buildup, and the distribution of disabilityspecific warning equipment. Lake County also implemented several changes to human resources procedures, including a shift in the organizational location of the Office of Emergency Services to ameliorate coordination and information challenges experienced during the fire, as well as a grief program for public safety professionals. The County also began a broad initiative to revise its emergency operations plan, which had not occurred in over 20 years.

Our topic analysis indicated that post-event local media coverage in Lake County was relatively focused (kurtosis $=2$ ), with climate change making up a relatively high percentage of topical coverage (4\%) compared to other cases. Interviewees tended to associate the fire and the preceding drought with climate change, while also indicating that climate change was not a direct cause of the fire. At the state level, California Governor Jerry Brown's acted as a statewide opinion leader, connecting 2015 wildfires throughout California to climate change:

After meeting with fire officials to receive an update on the Rocky Fire, which has burned almost 70,000 acres of wildland and destroyed dozens of homes, the governor used the opportunity to tie this year's fire season to climate change, calling it an existential threat that could potentially spark similar large-scale destruction in the future. He attributed the now four-year drought California faces to the extreme weather conditions brought by climate change. (Article 25)

These views were noted by local interviewees, including Project Coordinator for North Coast Opportunities Traci Boyle, who commented on the connections being made between the drought and climate change, “...because that's the conversation. Particularly, that's what the Governor on down is [saying and] all the state agencies are telling you" (Interview 61).

Not everyone agreed on the connection between climate change and the wildfire. Greg Giusti, for example, Director of University of California Cooperative Extension for LakeMendocino County and Advisor on Forests and Wildland Ecology, described the fire as "a result of 70 years of fire suppression and a weather event" (Interview 63). Moreover, Lake County also enacted at least one measure focused on achieving a rapid and comprehensive recovery, a relaxation of size requirements for lots and homes, highlighting the tension between human (re)development and disaster risk management in high-risk areas.

Most pointedly, Will Evans, Director of the Clear Lake Environmental Research Center, noted the distinct opportunity for change stemming from the wildfire, "It creates a policy window...the policy window has been open for a lot of stuff since the Valley Fire and then the floods this past year, like the whole Oroville Dam thing, another policy window opening up for more funding and changes to make things better." (Interview 59) 
Ultimately, interviewees described the resulting policy changes as having occurred in response to the risk of future disasters and related discussions, even though the community had not reached consensus on climate change's role in the fire.

\section{Recipe 2: Not democratic AND uncommon event}

The second causal combination yielded post-event policy change with a high degree of consistency (0.892) and moderate coverage (0.497). Cases representing this recipe included the three tornados in our sample-Cleveland County (OK), Laurel County (KY) and Winston County (MS) — as well as the Yavapai County (AZ) wildfire and the Richmond County (NY) hurricane.

The affected communities represented by this recipe were majority Republican counties that experienced high-impact and uncommon events. The Yavapai County (AZ) stands apart as an example of a case with a high number of emergency responder fatalities (a Hotshot crew), while the tornados resulted in a loss of citizen lives. Moreover, all the events stood out to those interviewed as being uncommon, either because the event was unusual for the area in terms of type/timing or because the event occurred in sequence with other extreme events in a recent timeframe.

Winston county (MS) The EF4 tornado that touched down in Winston County was part of a series of tornadoes that swept across Mississippi on April 28, 2014-the beginning of 5 days of severe weather in the state. All told, 23 tornadoes caused 14 deaths and damaged or destroyed approximately 2000 homes and 200 businesses. In the wake of the tornado, the communities in and around Winston County enacted two adaptation-focused policies, including application for and receipt of a federal grant for safe room construction at a local school and a new county policy to require every county building be insured. These policy measures were accompanied by ongoing efforts to map community structures, update emergency plans, and practice emergency operations drills. Winston County is predominantly Republican (54\%).

There was little evidence that the tornado led to climate change attention or increased awareness about climate change. Among all the cases, Winston County had one of the lowest levels of local media attention focused on the climate change topic (1\%), and less than a third of interviewees described community dialogue about climate change in the wake of the event. Interviewees indicated that climate change was not discussed in relation to the storm and attributed this to the fact that Mississippi is simply known for experiencing tornadoes. Indeed, Joseph McCain, editor of the Winston County Journal, indicated that, "I think most people here, they explained [the tornado] with religion not science" (Interview 20). Moreover, media attention was not singularly focused in the months after the event; the kurtosis measure was relatively high (19), indicating fairly diffuse attention.

That said, interviewees described a shift in the likely path of tornadoes, from Tornado Alley in the Midwest to Dixie Alley in the Southeast, and the need for new levels of awareness about potential risks, without explicitly linking the shift to climate change. For example, Buddy King, the Winston County Emergency Management Director, discussed how technology has improved our ability to predict severe weather and increased awareness of severe storms, without attributing the observed increase to climate change:

People are aware that this is happening. Mississippi has now become the leader in tornadoes. And even though Mississippi [has] a very rural nature...we're still having deaths because [of] the size and significance of the tornadoes. I don't know that it's 
new, but as our information increases in society, people are much more aware. (Interview 141)

Similarly, Lacy Vowell, Administrator of the Winston Medical Center Nursing Home, indicated that "I think things are changing and I think the intensity of any storm hitting anywhere in the world... you're just seeing bigger and worse" (Interview 145). Some interviewees indicated that after the 2014 series of tornados, there was a shift in community members' perceptions of future weather risks, noting that people are much more aware of the weather and its potential impacts. Mayor Hill shared the following thoughts: "You can see these things on the Weather Channel. You can see them on your regional or local news where it hits someone else. But when it hits you or hits your neighbor and hits your community, you realize the destruction." (Interview 140).

The evidence suggests that in the face of a high-impact event and shifting and unusual weather patterns, Winston County mobilized to address future risks via adaptation-oriented policy, despite a reluctance to frame those risks in terms of climate change and political orientations that eschew the science of anthropogenic climate change.

\section{Unexplained and contradictory cases}

The fsQCA process explained the occurrence of all ten cases of adaptation-oriented policy change. However, our analysis yielded one contradictory case, Suffolk County (NY), which was scored as being out of the set of cases that adopted adaptation-oriented policy, but which exhibits the conditions represented by the first recipe (Democratic AND Climate Change Attention). Suffolk County experienced "Winter Storm Nemo" in 2013, yielding several fatalities and a Presidential disaster declaration. Policy changes were adopted across multiple towns, most of which were focused on purchasing new snow removal equipment, although instances of updated planning and efforts to protect an incoming supply line were also recorded, yielding a fuzzy set score of 0.4 , just below the cutoff score of 0.5. The storm, however, came just on the heels of Hurricane Sandy (October 2012), which devastated the region and was readily linked to climate change, and indeed we observed that much of the climate change discussion was closely tied to that event.

\section{Recipes for policy stasis}

While our primary research question was focused on the conditions that lead to policy change, we used the same fsQCA process to examine the conditions that led to policy stasis. Five cases in our sample exhibited little to no policy change post-event, with two showing no evidence of post-event adaptation-oriented policy change: the heat events in Cook County (IL) and Clark County (NV). Minor policy measures were enacted after the Cook County (IL) cold event in the form of public transportation scheduling and notification policy, as well as disability-focused policy changes, while officials in St. Louis (MO) conducted post-event research on respiratory issues related to climate change. As noted above, changes enacted in Suffolk County (NY) included authorization for snow equipment purchase in multiple townships, as well as a plan to ensure a post-event supply line. While these policy changes were not irrelevant to these communities' needs, they did not meet our criteria for adaptation-oriented policy change.

We hypothesized that the same underlying conditions would be relevant for policy stasis. Our tests of necessity indicated no necessary conditions, although political orientation (Democratic) was a close contender. As such, we included all six conditions in our main 


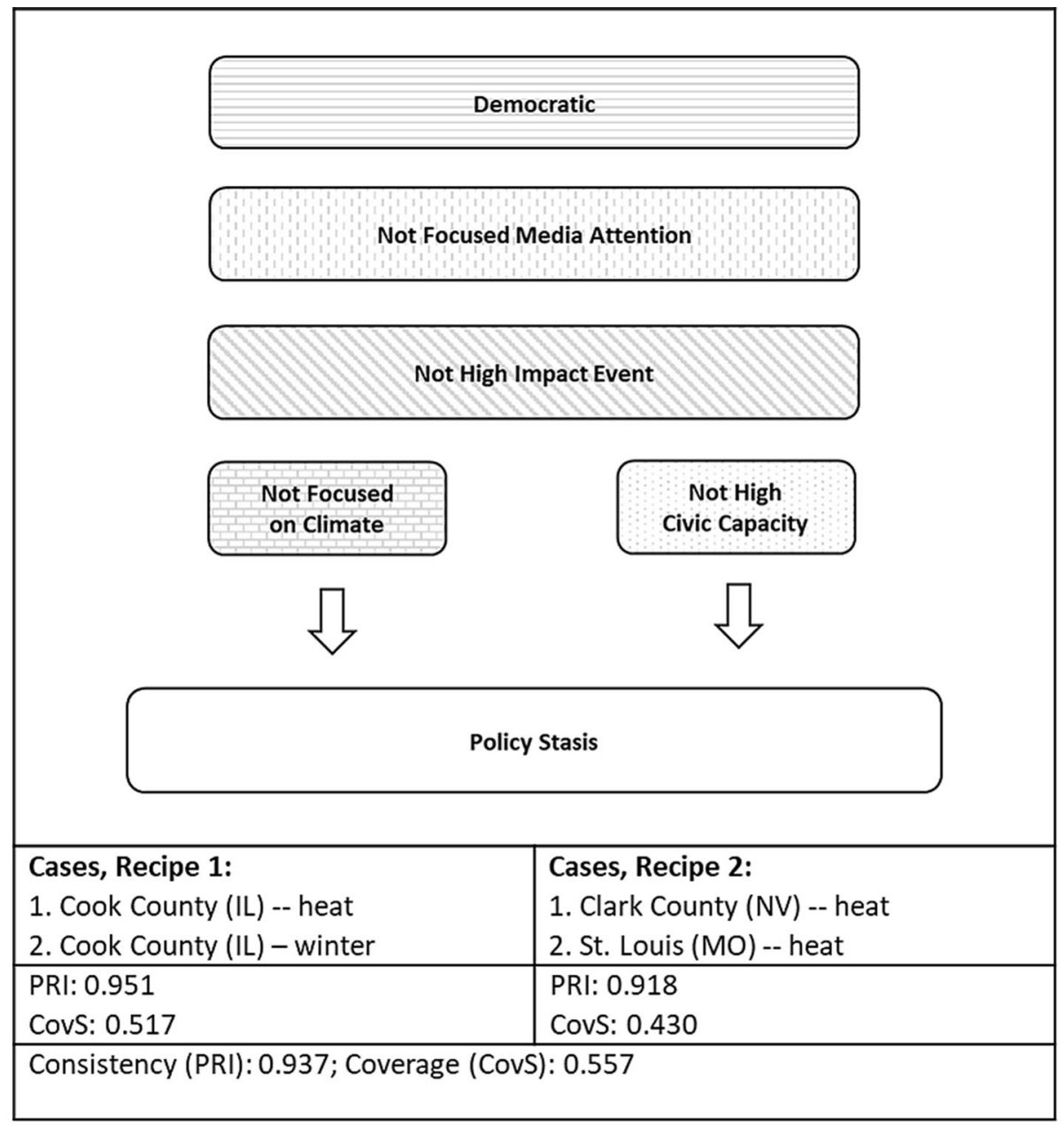

Fig. 6 Causal combinations related to post-event policy stasis

analysis, yielding two recipes for policy stasis, as shown in Fig. 6. The recipes share three conditions, suggesting that a Democratic community experiencing a non-impactful event that yields little attention is unlikely to show adaptation-oriented policy change in the wake of the event. The recipes differ only according to the last condition: (1) relatively low attention to the topic of climate change; or (2) low civic capacity.

These recipes are aligned with the qualitative evidence. The fifth case, Suffolk County (NY), remains unexplained, again likely due to the occurrence of that event within months of Hurricane Sandy, yielding high levels of lingering attention in affected communities. See Online Appendices A25-29 for results from our tests of necessity, directional expectations, tests of sufficiency, and sensitivity testing. 


\section{Discussion and conclusion}

We found substantial evidence of local adaptation-focused policy change in most caseson average, 5 measures per event - as well as distribution of those changes among the three major categories of policy change inspired by Cutter et al.'s (2012) report on local opportunities for advancing climate change adaptation. Almost half of the enacted measures were focused on anticipating and responding to future disaster risks, suggesting that these communities were able to orient themselves toward adaptation, even in the wake of significant disasters. Moreover, a considerable portion of policy efforts were directed at building local and regional capacity, especially among cases representing communities with conservative political orientations. However, none of our cases passed mitigation-focused policies, the overall number of policies remained fairly modest, and the policies themselves were heavily oriented toward the type of event that had been experienced (e.g., safe rooms for tornados). Furthermore, we find little evidence of policy change in communities that experienced low-impact events with low attention levels. In those cases, most of which were extreme temperature events, prior preparation levels may have contributed to both the low level of impact, as well as a strong sense of resiliency, thus alleviating the apparent need to adopt new policies.

There are admittedly limits to our analysis. Our 15 cases-which were purposively selected on the basis of impact, event type diversity, and media availability - are a non-representative sample of extreme weather events, which limits generalizability. That said, the use of fsQCA is not predicated on a representative sample; indeed, the method is intended as a case-based approach that takes advantage of existing diversity in the sample, yielding analytically generalizable results. Finally, our operationalization of the primary elements from our conceptual framework is undoubtedly imperfect; another fsQCA feature enables us to address this challenge, using our knowledge of these cases to calibrate our measures.

All told, our findings substantiate two enduring propositions for the policy change literature, including: (1) extreme events and disasters motivate policy change; and (2) agenda-setting matters. However, our findings also underscore the complexity and diversity of recipes for change highlighted by the disaster and risk management literature and suggest an unexpected path to adaptation among conservative communities that resist (or at least remain silent about) attributing extreme events to climate change. In those communities, the use of alternative framing may yield more adaptation-oriented change than climate change frames. Furthermore, policy adoption alone does not necessarily mean effective implementation or use of best practices (Cutter et al. 2012). We note the fairly narrow scope of the observed policy changes, suggesting that extreme events may trigger discovery of new policy tools and designs, or "instrumental learning," (May 1992) without yielding deeper social and political change. Finally, while all of the communities represented by these cases were committed to recovery in the face of potential future risk, some adopted policies that were explicitly intended to facilitate rapid rebuilding, with little attention to longer-term risks, highlighting a paradox of policy change in the wake of an extreme weather event. Adoption of adaptation-focused policy measures inherently suggests a longterm commitment to community, even in the face of the future risk of disaster associated with climate change. ${ }^{12}$ Our analysis highlights the potential for adaptation-focused policy

\footnotetext{
12 Admittedly, framing adaptation as disaster risk reduction rather than climate policy might mean foregoing opportunities for serious debates around climate change, with adverse consequences for long-term climate action. But such long-term risk exists should be weighed against the pressing need for adaptation policy-however it is framed-in the near term. Such an assessment is beyond the scope of this study, however.
} 
change in the wake of extreme weather events, even in communities that otherwise exhibit a strong avoidance of climate change discussion. Borrowing from the old adage, perhaps climate change adaptation by any other name smells equally sweet.

Acknowledgements We greatly appreciate the contributions made by our interview participants. We also express our thanks for the data collection contributions made by N. Downing, C. Flathers, J. Knobloch, R. Nilson, H. Satein, S. Shepard, H. Whitley, I. Widiyasari, and C. Zanocco, as well as guidance from J. Flora and D. McAdam. This work was supported by a grant from the National Science Foundation, Sociology Program (No. 1357055).

\section{References}

Albright, E. A., \& Crow, D. (2019). Beliefs about climate change in the aftermath of extreme flooding. Climatic Change. https://doi.org/10.1007/s10584-019-02461-2.

Allen, M. R., et al. (2018). Framing and context. In Global warming of $1.5^{\circ} \mathrm{C}$. An IPCC special report on the impacts of global warming of $1.5^{\circ} \mathrm{C}$ above pre-industrial levels and related global greenhouse gas emission pathways, in the context of strengthening the global response to the threat of climate change, sustainable development, and efforts to eradicate poverty. https://www.ipcc.ch/sr15/. 3 June 2019.

Birkland, T. A. (1997). After disaster: Agenda setting, public policy, and focusing events. Washington, DC: Georgetown University Press.

Birkland, T. A. (1998). Focusing events, mobilization, and agenda setting. Journal of Public Policy, 18(1), $53-74$.

Birkland, T. A. (2006). Lessons of disaster: Policy change after catastrophic events. Washington, DC: Georgetown University Press. http://ebookcentral.proquest.com/lib/osu/detail.action?docID=547783. April 18, 2019.

Birkland, T. A., \& Warnement, M. K. (2016). Refining the idea of focusing events in the multiple-streams framework. In R. Zohlnhöfer \& F. Rüb (Eds.), Decision-making under ambiguity and time constraints: Assessing the multiple-streams framework. Colchester: ECPR Press.

Blei, D. M., Ng, A. Y., Jordan, M. I., \& Edu, J. B. (2003). Latent Dirichlet allocation. Journal of Machine Learning Research, 3, 993-1022.

Boin, A. (2009). The new world of crises and crisis management: Implications for policymaking and research. Review of Policy Research, 26(4), 367-377.

Boin, A., t' Hart, P., \& McConnell, A. (2009). Crisis exploitation: Political and policy impacts of framing contests. Journal of European Public Policy, 16(1), 81-106.

Boudet, H., Giordono, L., Zanocco, C., Satein, H., \& Whitley, H. (2019). Event attribution and partisanship shape local discussion of climate change after extreme weather. Nature Climate Change, 10(1), 69-76. https://doi.org/10.1038/s41558-019-0641-3.

Center for Emergency Management and Homeland Security. (2018). The spatial hazard events and losses database for the United States, version 17.0 (Online Database). http://www.sheldus.org.

Cody, E. M., Stephens, J. C., Bagrow, J. P., Dodds, P. S., \& Danforth, C. M. (2017). Transitions in climate and energy discourse between Hurricanes Katrina and Sandy. Journal of Environmental Studies and Sciences, 7(1), 87-101. https://doi.org/10.1007/s13412-016-0391-8.

Cohen, J. (1960). A coefficient of agreement for nominal scales. Educational and Psychological Measurement, 20(1), 37-46.

COMPArative Methods for Systematic Cross-Case Analysis. (2017). COMPASSS statement on rejecting article submissions because of QCA solution type I COMPASSS. http://compasss.org/ blog/2017/08/16/\% ef\%bb\%bfcompasss-statement-on-rejecting-article-submissions-because-of-qcasolution-type/. Accessed 6 Apr 2020.

Crow, D. A., et al. (2018). Do disasters lead to learning? Financial policy change in local government: Do disasters lead to learning? Review of Policy Research, 35(4), 564-589.

Cutter, S., et al. (2012). Managing the risks from climate extremes at the local level. In C. B. Field, V. Barros, T. F. Stocker, \& Q. Dahe (Eds.), Managing the risks of extreme events and disasters to advance climate change adaptation (pp. 291-338). Cambridge: Cambridge University Press. https://www. cambridge.org/core/product/identifier/CBO9781139177245A046/type/book_part. May 8, 2019.

Cutter, S., et al. (2018). Compound, cascading, or complex disasters: What's in a name? Environment Science and Policy for Sustainable Development, 60(6), 16-25. 
Darr, J. P., Cate, S. D., \& Moak, D. S. (2019). Who'll stop the rain? Repeated disasters and attitudes toward government. Social Science Quarterly, 100(7), 2581-2593.

Demski, C., et al. (2017). Experience of extreme weather affects climate change mitigation and adaptation responses. Climatic Change, 140(2), 149-164.

Dunlap, R. E., \& McCright, A. M. (2008). Social movement identity: Validating a measure of identification with the environmental movement*. Social Science Quarterly, 89(5), 1045-1065.

Faries, D. (2015a). Recovery-More than 2300 register with FEMA. Lake County Record Bee: 1.

Faries, D. (2015b). Valley fire-Sheriff: 'Worst tragedy I've seen'. Lake County Record Bee: 1.

Flavelle, C. (2020). Conservative states seek billions to brace for disaster. (Just Don't Call It Climate Change.). The New York Times. https://www.nytimes.com/2020/01/20/climate/climate-change-fundi ng-states.html. January 20, 2020.

Hamilton, L. C. (2011). Education, politics and opinions about climate change evidence for interaction effects. Climatic Change, 104(2), 231-242.

Hamilton, L. C., et al. (2016). Flood realities, perceptions and the depth of divisions on climate. Sociology, 50(5), 913-933.

Hampton, J. (2013). Officials vow not to quit looking until everyone is found. The Moore American.

Henstra, D. (2012). Toward the climate-resilient city: Extreme weather and urban climate adaptation policies in two Canadian provinces. Journal of Comparative Policy Analysis: Research and Practice, 14(2), 175-194.

Howe, P. D., Boudet, H., Leiserowitz, A., \& Maibach, E. W. (2014). Mapping the shadow of experience of extreme weather events. Climatic Change, 127(2), 381-389.

Javeline, D., Kijewski-Correa, T., \& Chesler, A. (2019). Does it matter if you 'believe' in climate change? Not for coastal home vulnerability. Climatic Change, 155(4), 511-532.

King, G., Robert, R. O., Keohane, O., \& Verba, S. (1994). Designing social inquiry: Scientific inference in qualitative research. Princeton, NJ: Princeton University Press.

Kingdon, J. W. (1984). Agendas, alternatives, and public policies. Boston: Little, Brown.

Kinney, M. (2013). Tornado leaves moore in shambles, but not broken-Walking the path of devastation. The Moore American.

Krohn, K. (2015). Evacuees making the best of it. Lake County Record Bee: 1.

Lake County Record Bee. (2015a). Recovery-NCO relief fund provides $\$ 700,000$ to Date. Lake County Record Bee: 2.

Lake County Record Bee. (2015b). Recovery-Thompson secures funds for damaged roads, highways. Lake County Record Bee: 1.

Lake County Record Bee. (2015c). Valley fire: Emergency aid-FEMA declares state of emergency-will help pay for firefighting efforts. Lake County Record Bee: 5.

Lang, C. (2014). Do weather fluctuations cause people to seek information about climate change? Climatic Change, 125(3), 291-303.

Levendusky, M. S., Pope, J. C., \& Jackman, S. D. (2008). Measuring district-level partisanship with implications for the analysis of US elections. The Journal of Politics, 70(3), 736-753.

Lukes, S. (2005). Power: A radical view (2nd ed.). New York: Palgrave Macmillan.

Marquart-Pyatt, S. T., McCright, A. M., Dietz, T., \& Dunlap, R. E. (2014). Politics eclipses climate extremes for climate change perceptions. Global Environmental Change, 29, 246-257.

May, P. J. (1991). Reconsidering policy design: Policies and publics. Journal of Public Policy, 11(2), $187-206$.

May, P. J. (1992). Policy learning and failure. Journal of Public Policy, 12(4), 331-354.

McAdam, D. (2017). Social movement theory and the prospects for climate change activism in the United States. Annual Review of Political Science, 20(1), 189-208.

McAdam, D., \& Boudet, H. (2012). Putting social movements in their place: Explaining opposition to energy projects in the United States, 2000-2005. Cambridge: Cambridge University Press.

McEvoy, D., Fünfgeld, H., \& Bosomworth, K. (2013). Resilience and climate change adaptation: The importance of framing. Planning Practice and Research, 28(3), 280-293.

McHugh, M. L. (2012). Interrater reliability: The kappa statistic. Biochemia Medica, 22, 276-282.

Meerow, S., \& Neuner, F. (2019). Positively resilient? Public perceptions of urban resilience (p. 6033). Chicago, IL.

Mullin, M., \& Rubado, M. E. (2017). Local response to water crisis: Explaining variation in usage restrictions during a texas drought. Urban Affairs Review, 53(4), 752-774.

National Academies of Sciences, Engineering, and Medicine. (2016). Attribution of extreme weather events in the context of climate change. Washington, DC: The National Academies Press. https://doi. org/10.17226/21852. 
National Center for Charitable Statistics. (2019). NCCS data archive (dataset). https://nccs.urban.org/. March 19, 2019.

NOAA National Centers for Environmental Information (NCEI). n.d. US billion-dollar weather and climate disasters. https://www.ncdc.noaa.gov/billions/.

Nohrstedt, D. (2008). The politics of crisis policymaking: Chernobyl and Swedish nuclear energy policy. Policy Studies Journal, 36(2), 257-278.

Nohrstedt, D. (2011). Shifting resources and venues producing policy change in contested subsystems: A case study of swedish signals intelligence policy. Policy Studies Journal, 39(3), 461-484.

Nohrstedt, D., \& Parker, C. (2014). The public policy dimension of resilience in natural disaster management: Sweden's Gudrun and per storms. In N. Kapucu \& K. Liou (Eds.), Disaster and Development. Environmental Hazards (pp. 235-253). Cham: Springer. https://doi.org/10.1007/978-3-31904468-2_14.

Nohrstedt, D., \& Weible, C. M. (2010). The logic of policy change after crisis: Proximity and subsystem interaction. Risk, Hazards and Crisis in Public Policy, 1(2), 1-32.

Orlove, B., et al. (2019). Framing climate change in frontline communities: Anthropological insights on how mountain dwellers in the USA, Peru, and Italy adapt to glacier retreat. Regional Environmental Change, 19(5), 1295-1309.

Palutikof, J. P., Street, R. B., \& Gardiner, E. P. (2019). Decision support platforms for climate change adaptation: An overview and introduction. Climatic Change, 153(4), 459-476.

Plein, C. (2019). Resilience, adaptation, and Inertia: Lessons from disaster recovery in a time of climate change. Social Science Quarterly. http://onlinelibrary.wiley.com/doi/abs/10.1111/ssqu.12658. May 2,2019 .

Quirino, B. (2015). Containment expected next week. Lake County Record Bee: 1.

Ragin, C. C. (1987). The comparative method: Moving beyond qualitative and quantitative strategies. Berkeley: University of California Press. http://ebookcentral.proquest.com/lib/osu/detail.actio $\mathrm{n}$ ?docID=1698820. April 17, 2018.

Ragin, C. C. (2000). Fuzzy-set social science. Chicago: University of Chicago Press.

Ragin, C. C. (2006). Set relations in social research: Evaluating their consistency and coverage. Political Analysis, 14(3), 291-310.

Ragin, C. C. (2008a). Measurement versus calibration: A set-theoretic approach. In The Oxford handbook of political methodology, Oxford: Oxford University Press. http://www.oxfordhandbooks.com/ view/10.1093/oxfordhb/9780199286546.001.0001/oxfordhb-9780199286546-e-8. March 14, 2017.

Ragin, C. C. (2008b). Redesigning social inquiry: Fuzzy sets and beyond. Chicago: University of Chicago Press.

Reinhardt, G. Y., \& Ross, A. D. (2019). Expanding social science through disaster studies. Social Science Quarterly. http://onlinelibrary.wiley.com/doi/abs/10.1111/ssqu.12668. May 16, 2019.

Rudel, T. K. (2019). Shocks, states, and sustainability: The origins of radical environmental reforms. New York: Oxford University Press.

Schneider, C. Q., \& Wagemann, C. (2012). Set-theoretic methods for the social sciences: A guide to qualitative comparative analysis. Cambridge: Cambridge University Press. http://ebooks.cambr idge.org/ref/id/CBO9781139004244. April 24, 2018.

Shepard, S., et al. (2018). Community climate change beliefs, awareness, and actions in the wake of the September 2013 flooding in boulder county, Colorado. Journal of Environmental Studies and Sciences, 8(3), 312-325.

Sisco, M. R., Bosetti, V., \& Weber, E. U. (2017). When do extreme weather events generate attention to climate change? Climatic Change, 143(1), 227-241.

Smith, M., \& Schwartz, J. (2019). In flood-hit midwest, mayors see climate change as a subject best avoided. The New York Times. https://www.nytimes.com/2019/05/15/us/midwest-flooding-climatechange.html. August 16, 2019.

Tangney, P., \& Howes, M. (2016). The politics of evidence-based policy: A comparative analysis of climate adaptation in Australia and the UK. Environment and Planning C: Government and Policy, 34(6), 1115-1134.

Thomann, E., \& Maggetti, M. (2017). Designing research with qualitative comparative analysis (QCA): Approaches, challenges, and tools. Sociological Methods and Research: 004912411772970.

Tiernan, A., et al. (2019). A review of themes in disaster resilience literature and international practice since 2012. Policy Design and Practice, 2(1), 53-74.

Tierney, K. J. (2007). From the margins to the mainstream? Disaster research at the crossroads. Annual Review of Sociology, 33(1), 503-525.

US Census Bureau. Social explorer: 2011-15 American Community survey 5-year estimates. 
van der Heijden, J. (2017). Innovations in urban climate governance: Voluntary programs for low-carbon buildings and cities. Cambridge: Cambridge University Press. http://ebooks.cambridge.org/ref/id/ CBO9781108233293. June 5, 2019.

Vogel, B., \& Henstra, D. (2015). Studying local climate adaptation: A heuristic research framework for comparative policy analysis. Global Environmental Change, 31, 110-120.

Wang, X., \& Kapucu, N. (2008). Public complacency under repeated emergency threats: Some empirical evidence. Journal of Public Administration Research and Theory, 18(1), 57-78.

Zanocco, C., Boudet, H., Nilson, R., \& Flora, J. (2019). Personal harm and support for climate change mitigation policies: Evidence from 10 US Communities Impacted by Extreme Weather. Global Environmental Change, 59, 101984.

Zanocco, C., et al. (2018). Place, proximity, and perceived harm: Extreme weather events and views about climate change. Climatic Change, 149(3-4), 349-365.

Publisher's Note Springer Nature remains neutral with regard to jurisdictional claims in published maps and institutional affiliations.

\section{Affiliations}

\section{Leanne Giordono ${ }^{1}\left[\right.$. Hilary Boudet ${ }^{1} \cdot$ Alexander Gard-Murray $^{2}$}

1 Oregon State University, Corvallis, USA

2 Harvard University, Cambridge, USA 